\title{
EFFECTS OF AN EXERCISE PROGRAMME ON Non-Insulin DePendant Diabetes Mellitus
}

\begin{abstract}
Introduction: The best approach in minimising or delaying the complications associated with type 2 diabetes mellitus (NIDDM) in South African physiotherapy rehabilitation services has not been established. Physiotherapists continue to rehabilitate amputees as a result of diabetes mellitus. As hospital costs continue to rise every year, it becomes very costly to keep the patients for longer periods.

A study was undertaken at the Bethlehem Regional Hospital in the Free State to determine the effects of supervised and unsupervised exercise programmes in patients with non insulin dependant (type 2) diabetes mellitus.
\end{abstract}

Aim: The purpose of this study was to evaluate the effects of the two different

\section{Mshunqane N, MSc' Cohen D, BSC, Kalk JK, PhD}

${ }^{1}$ Lecturer, Physiotherapy Department, Medunsa.

2 Physiotherapy Department, University of the Witwatersrand.

3 Department of Endocrinology, University of the Witwatersrand. exercise programmes i.e. hospital based and home based exercise programmes on patients with type 2 diabetes mellitus. Methodology: The hospital based programme consisted of supervised walking and cycling whilst the home based programme consisted of walking only. Changes in measures of obesity, exercise capacity, glycaemic control and plasma lipids were monitored before the exercise programme and 3 months after graded exercise programmes.

Results: The exercise programmes significantly improved exercise capacity, anthropometric measurements and blood glucose levels but had no effect on lipid profiles. There was similar improvements in all the groups but no difference was found when comparing the results between the groups.

Conclusion: Although there was no significant difference between the groups, it is concluded that, any form of low endurance exercise programme, whether supervised or unsupervised is beneficial for patients with type 2 diabetes mellitus.

KEY WORDS: TYPE2 DIABETES MELLITUS, EXERCISE PROGRAMME, BLOOD CHEMISTRY, ANTHROPOMETRIC MEASUREMENTS, EXERCISE CAPACITY (FITNESS).

A research report submitted to the Faculty of Health Sciences, University of the Witwatersrand, Johannesburg, in partial fulfilment of the requirements for the degree of Master of Science in Physiotherapy. Johannesburg, 2003

\section{ACKNOWLEDGEMENTS}

I am indebted to my supervisors, patients and everybody who made the study a success. I wish to express my sincere gratitude to Dr J Paiker for analyses of laboratory results, Dr P Becker for statistical analysis. The study was supported by a grant from Medical Research Council.

\section{CORRESPONDENCE TO:}

Nombeko Mshunqane

Physiotherapy Department

P.O. Box 239

Medunsa

0204

Tel: (012) 521-3847

E-mail: mshunqane@webmail.co.za

\section{INTRODUCTION}

Diabetes mellitus is one of the most prevalent non communicable diseases amongst the African population (Cooper et al, 1997). Type 2 diabetes mellitus is a disorder characterised by impairment in insulin action (insulin resistance) and secretion (Mourier et al, 1997). Diabetic prevalence rates suggest that increasing westernization and urbanization are responsible factors for diabetes as this results to changes in lifestyle and diet (Fujimoto et al, 2000). The prevalence of type 2 diabetes is also related to obesity, although the relationship differs for race and ethnicity.

The main characteristic of type 2 diabetes mellitus is impaired glucose homeostasis which is accompanied by varying degrees of abnormalities in insulin action, secretion and hepatic glucose production (Fujimoto et al, 2000). Genetic and lifestyle factors play an important role in the etiology of type 2 diabetes. Most people with type 2 diabetes mellitus are overweight and lead a sedentary life, both of which contribute to insulin resistance. Weight reduction and increased levels of physical activity improve insulin resistance and are important in the management of type 2 diabetes mellitus (Mourier et al, 1997). Family history indicates genetic risk factors whilst physical inactivity and diet (animal fat intake) indicate lifestyle factors (Fujimoto et al, 2000). The causes of insulin resistance can be influenced by impaired beta cell function, circulating insulin antagonists and target tissue defects in insulin action (Olefsky 
et al, 1981).Abnormal beta cells cannot fully compensate resulting in relative insulin deficiency and hyperglycaemia.

The persistent hyperglycaemia is known to be responsible for serious damage to large and small blood vessels together with various organs in type 2 diabetes such as retinopathy, nephropathy and neuropathy (Kikkawa, 2000). The disease also leads to damage to large vessels resulting in severe diseases such as myocardial infarction, cerebral infarction and gangrene.

The modalities of therapy for patients with type 2 diabetes include the following:

- Drugs in the form of insulin and oral hypoglycaemic agents.

- Hypocaloric or low carbohydrate diet.

- Exercise programmes using high or low endurance type activities.

Drugs play an important role in increasing insulin secretion and reducing insulin resistance. Hypocaloric diet results in weight loss and thus improving insulin sensitivity and glycaemic control. Exercises are the cornerstones in the treatment of patients with type 2 diabetes, hence these programmes are used primarily for prevention of the disease in patients at risk, secondary level for early intervention and tertiary level to prevent complications of the disease (Sato, 2000). Regular exercise improves exercise capacity, reduces levels of triglycerides, total cholesterol, glycosulated haemoglobin $\left(\mathrm{HbA}_{1 \mathrm{c}}\right)$ (Raz et al, 1994; Argurs-Collins et al, 1997). Individuals that participate in physical activities have higher levels of high density lipoprotein (HDL) cholesterol and lower levels of low density lipoprotein (LDL) cholesterol and triglycerides compared to sedentary individuals.

Walking as one of the exercises is safe, of moderate intensity, easy, cost effective and improves insulin sensitivity and reduces body weight, and is thus recommended for patients with type 2 diabetes (Frank et al, 2001).

Physiotherapists have been less involved in the multidisciplinary preventative treatment of patients with type 2 diabetes, but are involved in rehabilitation of the resultant complications of diabetes mellitus such as strokes and amputations. It is thus essential that the rehabilitation programmes are carried out by the patients themselves since the therapists are few compared to a number of patients who require rehabilitation. More attention in South Africa nowadays is given to community based health care, therefore there seems to be a great need for a cost effective, easy attainable instrument which can be used as outcomes measures for evidence based practise. Walking, because it is simple to use, inexpensive and safe should be encouraged in patients with type 2 diabetes (Krista, 2000).

\section{METHODOLOGY}

\section{Sample}

All patients attending the diabetic clinic at Bethlehem Regional hospital in the Free State. The study was conducted between the period of April to December 1999. The age group was between 40 - 60 years. Years of diabetes were not considered in this study, but only participants who were diagnosed for more than a year were included. A sample of convenience was used.

The total number of the patient group who attended a clinic comprised of 50 patients. Thirty patients $(60 \%)$ volunteered to participate in the study (18 females and 12 males). All the participants were on oral hypoglycaemic medication. Diet was not controlled by the researcher. The patients were randomly allocated to either a hospital based or a home based exercise programme.

\section{Design:}

Randomised intervention study.

\section{Objectives}

1. To evaluate the effects of two different exercise programmes in patients with type 2 diabetes on changes in:

- Exercise capacity

- Body weight

- Body circumferential measurements around hips and waist

- Blood chemistry

2. To compare the differences of the above effects in patients exercising with supervision and without supervision.

\section{Procedure}

A health questionnaire was completed before each individual started the objective baseline tests, to determine whether they could be included in the study.

\section{Inclusion/ Ex clusion criteria}

- Type 2 diabetes mellitus

- BMI > $27 \mathrm{~kg} / \mathrm{cm}^{2}$

- Oral hypoglycaemic medication

- Controlled BP (+- 140/90)

- No evidence of ischaemic heart diseases

- No peripheral vascular diseases.

- Ability to attend on stipulated dates.

Participants were randomly allocated to three groups using a stratified random sampling. The three groups were:

Group 1: Walking under supervision (done by the researcher) at the hospital.

Group 2: Walking unsupervised (done at home by participants without supervision).

Group 3: Cycling under supervision (done by the researcher) at the hospital.

The researcher assigned participants to the different groups.

The following baseline tests were completed for each subject before the exercise programme was started and at the end of the three months exercise programme.

\section{BLOOD SAMPLING}

Blood in an overnight fasting state was taken by a professional nurse for laboratory tests at the diabetic clinic at Bethlehem Regional Hospital. The levels of the following bloods were analysed:$\mathrm{HbA}_{1 \mathrm{c}}$ /Fructosamine, blood glucose, $\mathrm{C}$-peptide and lipogram.

\section{ANTHROPOMETRIC MEASUREMENTS}

The following anthropometric measurements were taken by the researcher. Body weight was measured using a bathroom scale as this was the only available scale used in the hospital. The scale was not calibrated but the researcher zerod the scale after each participant.

Skin fold measurements were made using a skin fold meter at the following sites: - triceps, biceps, subscapular and supra-iliac regions (ACSM'S guidelines 
for exercise testing and prescription, 1995). Circumferential measurements were taken around the waist and hips using a tape measure, to determine the waist-hip ratio (ACSM'S guidelines for exercise testing and prescription, 1995).

\section{EXERCISE CAPACITY TEST}

This test was done to establish the baseline exercise fitness for the participants before they were engaged in an exercise programme.

The test was carried out on the day of the clinic with medical doctors in attendance. Subjects cycled for 3 minutes at a workload of 25 watts with continuous ECG monitoring. The heart rate and blood pressure were recorded at the end of every 3 minutes. The workload was increased by 25 watts every 3 minutes until the subject felt unable to exercise at a higher workload, or the heart rate has reached $80 \%$ of the age predicted maximum heart rate i.e.[80\%(220-age)] (ACSM'S guidelines for exercise testing and prescription, 1995).

\section{EXERCISE PROGRAMMES}

\section{Walking}

Time was used as the measurement of progression in exercise, since this was an easy and common measurable variable for all participants and the group was not experienced in taking their pulse. An exercise diary was given to all participants and they were asked to record the actual time taken to exercise. Participants were instructed to start off walking for a minimum of 10 minutes and were asked to try and build up their walking time to 30 minutes. At 4 weeks all participants were able to walk or cycle for 30 minutes on alternate days.

\section{Cyding}

Cycling was done using the bicycle ergometer under supervision at the hospital. The cycling pace was similar to walking. They exercised at a workload equal to $70 \%$ of their individual maximum heart rate (as was determined in the exercise capacity test previously). They initially exercised for 6 minutes until they were able to exercise for 30 minutes. At 4 weeks participants were able to exercise for 30 minutes on alternate days, this continued for a period of 3 months. This was a comfortable intensity for the group of patients since they were exercising without supervision.

\section{Statistical methods}

A paired t-test was used for comparison within groups and ANOVA for comparison between groups and to confirm randomisation. A p-value of $<0,05$ was regarded as statistical significant (Raz et al, 1994). Bartlett's test for equal variances was used by a statistician to analyse the differences between groups. The p-value was more than 0.05 confirming that the groups equally distributed (no difference in randomisation).

\section{Results}

The results of this study will be summarised using table 1 . This table shows the clinical data before the exercise programme and after three months of exercise. Twenty four participants completed the study and six dropped out. Three patients from the cycling group did not want their blood for investigations to be taken for the last time, and were excluded. One patient from home walking group had laparatomy and did not want to continue with exercise. One patient from hospital walking group did not keep the appointment and was excluded from the results.

\section{DISCUSSION}

All groups showed significant improvements in serum glucose levels $\mathrm{p}<0.05$. There was an increase in the exercise capacity, reduction in body weight and adipose tissue was also reduced. This was confirmed by the difference in skinfolds measurements when initial values were compared to final values. There was no difference whether these programmes were performed by the patient at home or supervised at the hospital $(\mathrm{p}>0.05)$.

Table 1: Clinical data of all patients $(n=24)$ before and after the exercise programme.

\begin{tabular}{|c|c|c|c|c|c|c|}
\hline & \multicolumn{2}{|c|}{$\begin{array}{c}\text { Home walking } \\
\text { (unsupervised) } n=9\end{array}$} & \multicolumn{2}{|c|}{$\begin{array}{l}\text { Hospital walking } \\
\text { (supervised) } n=8\end{array}$} & \multicolumn{2}{|c|}{$\begin{array}{c}\text { Cycling } \\
\text { (supervised) } n=7\end{array}$} \\
\hline & $\begin{array}{l}\text { Mean } \\
\text { Before }\end{array}$ & $\begin{array}{l}\text { Mean } \\
\text { After }\end{array}$ & $\begin{array}{l}\text { Mean } \\
\text { Before }\end{array}$ & $\begin{array}{l}\text { Mean } \\
\text { After }\end{array}$ & $\begin{array}{l}\text { Mean } \\
\text { Before }\end{array}$ & $\begin{array}{l}\text { Mean } \\
\text { After }\end{array}$ \\
\hline Age (years) & 54.0 & & 56.3 & & 48.9 & \\
\hline B.W. (Kg) & 80.3 & 77.9 & 80.1 & 75.9 & 87.4 & 78.0 \\
\hline B.M.I & 29.3 & 28.6 & 30.0 & 28.8 & 32.0 & 30.6 \\
\hline Waist Circumference (cm) & 98.3 & 95.3 & 102.3 & 96.0 & 103.6 & 102.0 \\
\hline Hip Circumference (cm) & 105.7 & 100.8 & 106.7 & 103.0 & 106.1 & 102.0 \\
\hline B.G (mmol/ () & 12.8 & 6.7 & 14.2 & 9.4 & 12.6 & 7.9 \\
\hline Fruc & 348.9 & 249.2 & 325.9 & 292.9 & 293.9 & 267.3 \\
\hline Max Power (watts) & 58.3 & 83.3 & 75.0 & 103.6 & 62.5 & 96.9 \\
\hline Max Heart Rate (b.p.m) & 130.7 & 109.3 & 138.4 & 106.4 & 134.8 & 104.1 \\
\hline $\begin{array}{l}\text { Max: maximum } \\
\text { Fruc: fructosamine }\end{array}$ & $\begin{array}{l}\text { : body } w \\
\text { l: body } n\end{array}$ & ndex & B.G & & & \\
\hline
\end{tabular}




\section{Exercise Capacity}

Studies on exercise capacity state that low exercise capacity is the most prevalent cause of mortality in patients with type 2 diabetes mellitus. This results in cardiovascular diseases which are life threatening. The low exercise capacity is as a result of inactivity or sedentary life that these patients are leading (Wei et al, 2000). The results of this study showed significant improvements in exercise capacity $(\mathrm{p}<0.05)$ in all groups. However when a comparison was made to establish a level of improvement between groups, no significant difference was demonstrated ( $p>0.05$ ). The results showed that the home based programme compared well with hospital based programme.

The study conducted by Raz et al (1994) showed significant improvements in exercise capacity after 12 weeks of an exercise programme on ergometer cycle or treadmill for 45 minutes. The experimental group showed improvement in exercise capacity and the control group showed no change. These results agree with the results of the present study as the amount of activity performed resulted in a change in exercise capacity. Although in the present study, patients exercised for 30 minutes, they all improved their exercise capacity regardless of home based or hospital based programme.

\section{Serum sample changes (glycaemic control)}

These are the changes measured in blood glucose levels. Patients with type 2 diabetes mellitus are characterized by impairment in insulin action (Taniguchi, 2000). The main characteristic of type 2 diabetes mellitus is impaired glucose tolerance and is usually associated with low levels of physical activity (Eriksson et al, 1997).

In the present study all groups showed a trend of improvement on the changes of the blood samples. However within group results showed reductions in blood glucose levels $(\mathrm{p}<0.05)$ in all the groups. There was an additional improvement in total cholesterol in home walking group $(\mathrm{p}<0.05)$ and LDL level $(\mathrm{p}<0.05)$ in hospital walking.

In the study conducted by Krotkiewski et al (1985) it was concluded that physical activity alters insulin secretion and effectiveness in obese patients with type 2 diabetes. This was indicated by a decrease in C-peptide (an indicator of insulin secretion) concentration. After 12 weeks of an exercise programme insulin secretion and glucose tolerance improved. This improvement occurred on patients with type 2 diabetes as well as normal subjects. In the present study no improvements were observed in C-peptide in all the groups. Only a trend of improvement was observed.

\section{Body weight and Anthropometric Measurements (measures of obesity)}

Obesity is a major characteristic of type 2 diabetes which has been shown to result in impaired insulin sensitivity. Exercise has been proven to increase insulin sensitivity in patients with type 2 diabetes mellitus (Frank et al, 2001).

In the present study, however, within group results showed significant reductions in all the parameters of body weight and anthropometric measurements in the cycling group $(\mathrm{p}<0.05)$. The groups did not all show significant differences when subjected to a comparison between body weight and anthropometric measurements $(p>0.05)$ after three months of exercise programme. Only changes in waist, subscapular and suprailiac measurements were observed in the hospital walking group $(p<0.05)$. All other variables except hip measurements ( $p>0.05$ ) in home walking group were significant $(\mathrm{p}<0.05)$. When a non parametric test was used to analyse these results in the total group of patients, however, there were significant improvements in all variables. This reduction in body weight may be explained by the fact that this group of subjects was very sedentary.

Bogardus et al (1984) compared the effect of physical training (walking, jogging, or aerobic dancing for 20-30 minutes) and diet to diet alone on body composition and glucose tolerance in patients with glucose intolerance and patients with type 2 diabetes mellitus. There were similar reductions in body weight, fat mass and fat-free mass but body fat distribution ratio was more decreased in the exercise and diet group compared to the diet alone group.
The reviewed literature showed that body weight and anthropometric measurements were directly affected by diet or eating habits. In our study, however, improvements in anthropometric measurements occurred even though, we did not consider diet.

\section{LIMITATIONS}

The sample size is small to generalise the results although these results show a trend of improvement.

\section{CONCLUSION}

The findings of this study have demonstrated that low endurance type exercise, like walking or cycling for 3 months, improved glycaemic control, exercise capacity, anthropometric measurements and body weight significantly. These results occurred whether the programme was supervised or not. Thus patients with type 2 diabetes mellitus can benefit equally from both a home based or a hospital based exercise programme.

\section{REFERENCES}

American Diabetes Association 1997 Diabetes mellitus and exercise. Diabetes Care 20(12): 1908-1912

Agurs-Collins TD, Kumanyika SK, Have TRT, Adams-Campbell LL 1997 A randomised controlled trial of weight reduction and exercise for diabetes management in older AfricanAmerican subjects. Diabetes Care 20(10): 1503-1511

Bogardus C, Ravussin E, Robbins DC, Wolfe RR, Horton ES, Sims EAH 1984 Effects of physical training and diet therapy on carbohydrate metabolism in patients with glucose intolerance and non-insulin dependant diabetes mellitus. Diabetes 33: 311-318

Cooper RS, Rotimi CN, Kaufman JS, Owoaje EE, Fraiser H 1997 Prevalence of NIDDM among populations of the African diaspora. Diabetes Care 20(3): 343-348

Frank B, Liu S, Stampfer MJ, Solomon C, Colditz G A, Speizer F E, Willet WC, Manson JE 2001 Physical activity and risk for cardiovascular events in diabetic woman. Annals of Internal Medicine 134(2): 96-105 
Fujimoto WY, Bergstrom RW, Boyko EJ, Kwang-Wen C, Kanh SE, Leonetti DL, McNeely MT, Newell LL, Shofer JB, Tsunehara CH, Walh PW 2000 Preventing diabetes applying pathophysiological and epidemiological evidence. British Journal of Nutrition 84: S173-S176

Kikkawa R 2000 Chronic complications in diabetes mellitus. British Journal of Nutrition 84: S183- S185

Krotkiewski M, Lonnroth P, Mandroukas K, Wroblewski Z, Rebuffe-Scriwe M, Holm G, Smith U, Bjorntorp P 1985 The Effects of physical training on insulin secretion and effectiveness and on glucose metabolism in obesity and type 2 (non-insulin-independent) diabetes mellitus. Diabetologia 28: 881- 890
Kriska A 2000 Physical activity and the prevention of type 2 diabetes mellitus - How much for how long? Sports Medicine 29(3): 147-151

Mourier A, Gautier J, Kerviler E, Bigard AX, Villette J, Garnier J, Duvallet A, Guezennec CY, Cathelineau G 1997 Mobilization of visceral adipose tissue related to the improvement in insulin sensitivity in response to physical training in NIDDM. Diabetes Care 20(3): 385-391

Raz I, Hauser E, Bursztyn M 1994 Moderate exercise improves glucose metabolism in uncontrolled elderly patients with non insulin dependent diabetes mellitus. Israel Journal of Medical Science 30(10): 766-770
Sato Y 2000 Diabetes and life style - Role of physical exercise for primary prevention. British Journal of Nutrition 84: S187- S190

Taniguchi A, Fukushima M, Sakai M, Nagasaka S, Doi K, Nagata I, Matsushita K, Ooyama Y, Kawamoto A, Nakasome M, Tokuyama K, Nakai Y 2000 Effects of physical training on insulin sensitivity in Japanese type 2 diabetes patients. Diabetic Care 23(6): 857-858

Wei W, Gibbons WL, Kampert BJ, Nichaman Z, Blair NS 2000 Low cardiopulmonary fitness and physical activity as predictors of mortality in men type 2 diabetes. Annals of Internal medicine 132: 605-611

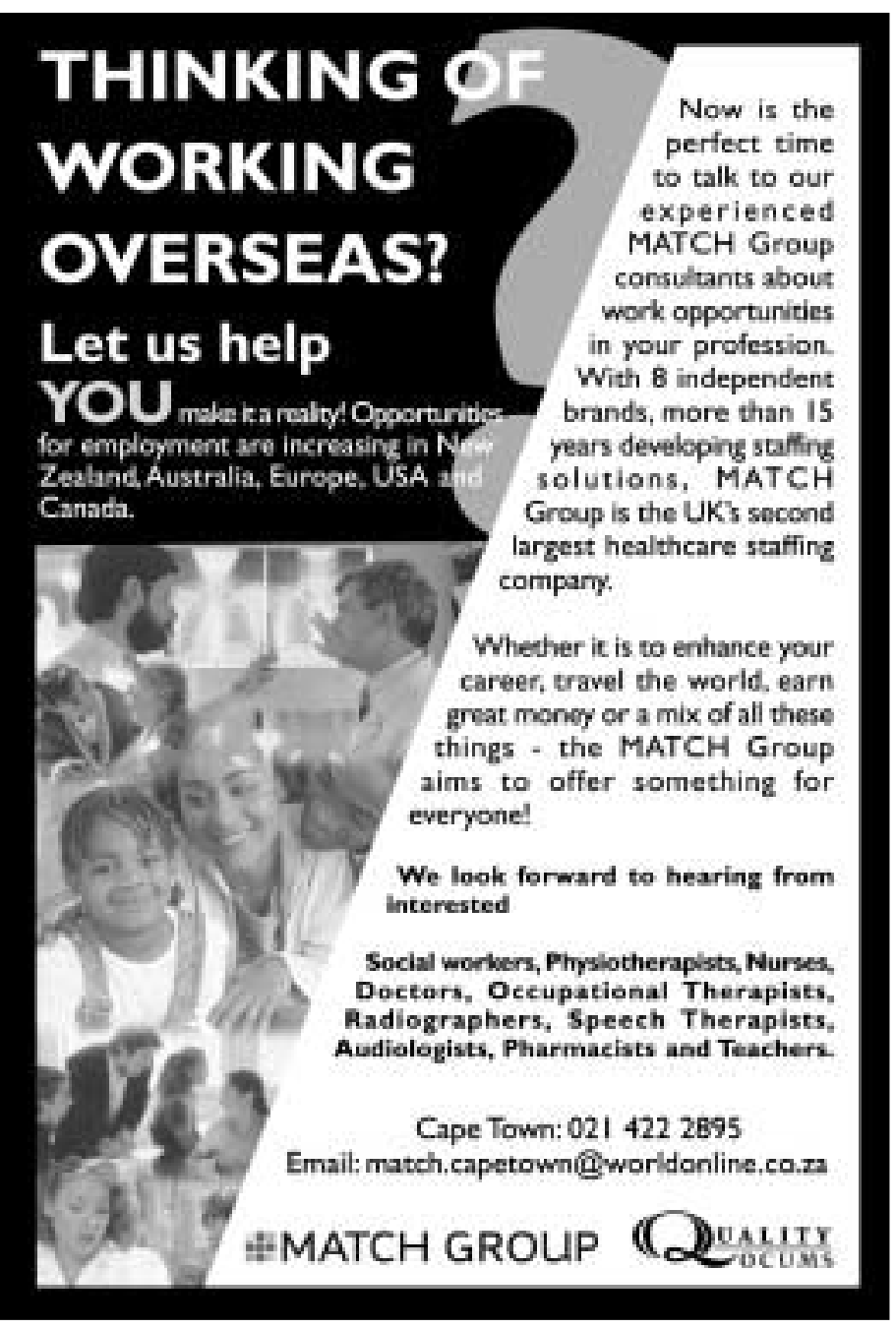

- Recommend BIOFREEZ to patients with
osteoarthritis, tendonitis, and general joint aching
and stiffness. Use it to prolong the therapeutic effects
of pain relief modalities, allow increased ROM during
stretching exercises, to decrease edema to shoulders
\& knees after trauma.
TRY B IOFREILABLE DIRECT FROM THE AGENT!
SPECIAL INTRODUCTORY OFFER.....
- PURCHASE 15 PATIENT TUBES OR ROLL-ONS
- AND WE'LL GIVE YOU...
- $125 \mathrm{gDDITIONAL}$ PROFESSIONAL PUMP
- 20 5g SAMPLES ...... AT A REDUCED RATE!
For more info and samples call:
Steve Henson on 011-442-7799 or 083-989-0704

